\title{
PREDICTION OF REACTION RATE CONSTANTS OF HYDROXYL RADICAL WITH ORGANIC COMPOUNDS
}

\author{
ZHEN CHEN ${ }^{1}$, XINLIANG YU ${ }^{*}, 1$ XIANWEI HUANG ${ }^{1}$ AND SHIHUA ZHANG ${ }^{* 1,2}$ \\ ${ }^{1}$ College of Chemistry and Chemical Engineering, Hunan Institute of Engineering, Xiangtan, Hunan 411104, China \\ ${ }^{2}$ Network Information Center, Hunan Institute of Engineering, Xiangtan, Hunan 411104, China
}

(Received: June 21, 2012 - Accepted: January 21, 2013)

\begin{abstract}
In this work we have performed a QSAR study of atmospheric reactions with hydroxyl radical, at the B3LYP level of theory with 6-31G(d) basis set. Molecular descriptors selected by applying multiple linear stepwise regression (MLR) analysis were used to predict the reaction rate constants (-log $k_{\mathrm{OH}}$ ) of $\mathrm{OH}$ radicals with organic compounds in the atmosphere, including 98 alkenes and 80 aromatic compounds. For setting our reactions, we have calculated 98 alkenes and 80 aromatic compounds. A four-descriptor MLR model ( $r m s=0.102$ and $\left.R^{2}=0.938\right)$ for 98 alkenes was developed based on the number of $\mathrm{R}=\mathrm{CHX}$ functional group counts, $E_{\text {номо }}$ parameter, and Fukui indices of the double-bonded C atoms. We found vinyl chemicals with conjugated double bonds and electron-donor substituents are the most reactive systems; while alkenes with multiple halogen substitutions are the least reactive molecules. Additionally, a three-descriptor MLR model $(r m s=0.282$ and $R^{2}=0.910$ ) was built to predict $\mathrm{OH}$ radical rate constants for 80 aromatic compounds, which was dominated by the $E_{\text {номо }}$ parameter, a topological descriptor for steric hindrance, and the most positive net atomic charge on hydrogen atoms. Aromatics with electron-donor and electron-acceptor groups, respectively, possess high and low degradation rates. The halogen aromatics are less reactive, especially for aromatics with multiple halogen substitutions. In comparison to existing models, the two models obtained in this paper show better statistical quality.
\end{abstract}

Keywords: alkenes; aromatics; density functional theory; quantum chemical; structure-activity relationships; rate constant.

\section{INTRODUCTION}

In recent decades, large amounts of organic compounds have emitted into the atmosphere. They may cause photochemical air pollution, acid deposition, long-rang transport of chemicals, changes of the stratospheric ozone layer, global weather modification, etc., through a complex array of chemical and physical transformations. ${ }^{1}$ These chemicals can be chemically transformed in the troposphere by reactions with photochemically generated oxidants like $\mathrm{OH}$ radicals and ozone during the daytime and $\mathrm{NO}_{3}$ radicals at night. ${ }^{2-4}$

The reactions of organic pollutants with ${ }^{\circ} \mathrm{OH}$ in the atmosphere is of great concern because it is the primary process for their degradation and transformation in the daytime, and the behavior and fate of organic compounds in the atmosphere should be assessed according to their reaction rate constants. But only a limited number of experimentally measured rate constants are available. Moreover, all the experimental methods are time-consuming, laborious, costly and equipment dependent. ${ }^{5}$ Reaction rates can be predicted with quantitative structure-activity relationship (QSAR) models. ${ }^{6}$ QSAR is the process by which molecular structural descriptors are quantitatively correlated with chemical properties or activities of molecules. Being cost-effective and rapid estimation methods, several QSAR models have been successfully developed for predicting the rate constants of many structural heterogeneous compounds with ${ }^{\circ} \mathrm{OH}$ radicals, ${ }^{7-15} \mathrm{NO}_{3}$ radicals and $\mathrm{O}_{3}{ }^{15-18}$

Bakken and Jurs developed five-descriptor QSAR models for $k_{\mathrm{OH}}$ of 57 unsaturated hydrocarbons and ten-descriptor QSAR models for 312 compounds with multiple linear regression (MLR) and artificial neural networks (ANNs). Pompe et al. used topological indices to develop a 6-parameter MLR model $(r m s=0.115)$ for $k_{\mathrm{OH}}$ of 58 unsaturated organic compounds. ${ }^{8}$ Gramatica et al. constructed three MLR models for $k_{\mathrm{OH}}$ with 4-6 predictor variables. ${ }^{9,10}$
The prediction rms errors were not less than $0.4 \log$ units. Öberg developed a QSAR model with partial least squares (PLS) regression. The model had the prediction standard error of $0.501 \mathrm{log}$ units, through selecting 333 descriptors and compressing to 7 latent variables. ${ }^{11}$ Recently, Fatemi and Baher successfully developed six QSAR models for $k_{\mathrm{OH}}$ of 98 alkenes, by applying several chemometric tools including MLR, genetic algorithms (GAs), ANNs and support vector machines (SVMs). ${ }^{12}$ Wang et al. used 22 molecular descriptors to build a PLS model having a rms error of 0.430 for the test set. ${ }^{13}$

All the models stated above are based on molecular structures that were optimized with semi-empirical quantum chemistry methods, AM1 or PM3. In addition, QSAR models based on ANNs or SVMs possess complicated structures, which are unfavorable to extension and application of the models. The aim of this paper is to produce new robust QSAR models for $k_{\mathrm{OH}}$ of 98 alkenes and 80 aromatics, by applying the density functional theory (DFT) for geometry optimization.

\section{COMPUTATIONAL DETAILS}

\subsection{Data collection}

The experimental rate constants $\left(k_{\mathrm{OH}}\right)$ for the reactions of $\mathrm{OH}$ radical with 98 alkenes ${ }^{12}$ and 80 aromatics ${ }^{13}$ are listed in Tables 1 and 2 respectively. These alkenes have been studied by Fatemi and Baher. ${ }^{12}$ Experimental values were measured at $25^{\circ} \mathrm{C}$ and $101.3 \mathrm{kPa}$ and reported in $\mathrm{cm}^{3} \mathrm{~s}^{-1}$ molecule ${ }^{-1}$. To obtain positive values for $k_{\mathrm{O}}$, the listed numerical values were the negative logarithm of experimental $k_{\mathrm{OH}}$ values reported. The two entire sets contained a wide range of rate constant values, and were characterized by a high degree of structural variety. The experimental $-\log k_{\mathrm{OH}}$ data in each table were split into a training set $(50 \%)$ and a test set $(50 \%)$. The training set was used to develop a MLR model, which was validated with the test set.

Table 1. Molecular descriptors and $-\log k_{\mathrm{OH}}$ values for 98 alkenes.

\begin{tabular}{|c|c|c|c|c|c|c|c|}
\hline No. & Name & $f_{1 \mathrm{C}}$ & $f_{2 \mathrm{C}}^{\prime}$ & $N_{\mathrm{X}}$ & $E_{\text {номо }}$ & Exp. & Pred. \\
\hline & Training set & & & & & & \\
\hline 1 & $\alpha$-Phellandrene & -0.105505 & -0.011451 & 0 & -0.201328 & 9.50 & 9.74 \\
\hline 2 & trans-Ocimene & -0.057367 & -0.083843 & 0 & -0.214890 & 9.60 & 9.79 \\
\hline 3 & Terpinolene & -0.038062 & -0.025215 & 0 & -0.215923 & 9.65 & 9.72 \\
\hline 4 & $1-3-5-H e x a t r i e n e$ & -0.099162 & -0.081043 & 0 & -0.209238 & 9.66 & 9.84 \\
\hline 5 & $2-5-$ Dimethyl-2-4-hexadiene & -0.039113 & -0.050633 & 0 & -0.194584 & 9.68 & 9.51 \\
\hline 6 & $\gamma$-Terpinene & -0.067472 & -0.029318 & 0 & -0.217922 & 9.75 & 9.82 \\
\hline
\end{tabular}




\begin{tabular}{|c|c|c|c|c|c|c|c|}
\hline 7 & 1-3-Cyclohexadiene & -0.089259 & -0.158518 & 0 & -0.205526 & 9.79 & 9.82 \\
\hline 8 & cis-2-trans-4-Hexadiene & -0.100778 & -0.127656 & 0 & -0.207100 & 9.81 & 9.85 \\
\hline 9 & 1-3-Cycloheptadiene & -0.037108 & -0.198453 & 0 & -0.216948 & 9.86 & 9.82 \\
\hline 10 & trans-trans-2-4-Hexadiene & -0.094374 & -0.124102 & 0 & -0.205513 & 9.87 & 9.81 \\
\hline 11 & 2-3-Dimethyl-1-3-butadiene & -0.138670 & 0.000397 & 0 & -0.224837 & 9.91 & 10.07 \\
\hline 12 & $\beta$-Caryophyllene & -0.053939 & -0.023733 & 0 & -0.219970 & 9.92 & 9.81 \\
\hline 13 & 1-5-Dimethyl-1-5-hexadiene & -0.092121 & -0.008002 & 0 & -0.233258 & 9.92 & 10.04 \\
\hline 14 & trans-1-3-Hexadiene & -0.119738 & -0.109274 & 0 & -0.215871 & 9.95 & 9.98 \\
\hline 15 & 2-3-Dimethyl-2-butene & -0.070417 & -0.070417 & 0 & -0.217816 & 9.96 & 9.85 \\
\hline 16 & Dimethylketene & -0.115355 & -0.184448 & 0 & -0.211921 & 9.97 & 9.97 \\
\hline 17 & 2-Methyl-1-3-butadiene & -0.144574 & -0.000815 & 0 & -0.226117 & 10.00 & 10.10 \\
\hline 18 & 1-4-Cyclohexadiene & -0.053513 & -0.162187 & 0 & -0.226180 & 10.00 & 9.94 \\
\hline 19 & trans-1-3-Pentadiene & -0.122774 & -0.114538 & 0 & -0.216601 & 10.00 & 10.00 \\
\hline 20 & 2-3-Dimethyl-2-pentene & -0.079994 & -0.081041 & 0 & -0.211185 & 10.01 & 9.81 \\
\hline 21 & 1-Methylcyclohexene & -0.127708 & -0.057063 & 0 & -0.224366 & 10.03 & 10.07 \\
\hline 22 & 2-Methyl-2-pentene & -0.126040 & -0.060845 & 0 & -0.221978 & 10.04 & 10.04 \\
\hline 23 & trans-1-4-Hexadiene & -0.074911 & -0.100508 & 0 & -0.230689 & 10.04 & 10.01 \\
\hline 24 & 2-Methyl-2-butene & -0.123392 & -0.051252 & 0 & -0.225635 & 10.06 & 10.07 \\
\hline 25 & 2-Heptene & -0.109973 & -0.237771 & 0 & -0.230412 & 10.07 & 10.17 \\
\hline 26 & 2-Methyl-1-4-pentadiene & -0.074836 & -0.090135 & 0 & -0.239354 & 10.10 & 10.10 \\
\hline 27 & Cycloheptene & -0.103264 & -0.231826 & 0 & -0.232142 & 10.13 & 10.17 \\
\hline 28 & cis-4-Octene & -0.114484 & -0.243781 & 0 & -0.231550 & 10.14 & 10.20 \\
\hline 29 & trans-4-Octene & -0.109421 & -0.235237 & 0 & -0.229560 & 10.16 & 10.16 \\
\hline 30 & Cyclohexene & -0.112426 & -0.248897 & 0 & -0.233459 & 10.17 & 10.21 \\
\hline 31 & trans-2-Pentene & -0.110031 & -0.237968 & 0 & -0.230681 & 10.17 & 10.17 \\
\hline 32 & cis-2-Pentene & -0.115148 & -0.245782 & 0 & -0.232569 & 10.18 & 10.21 \\
\hline 33 & 4-Methyl-1-cyclohexene & -0.112632 & -0.247476 & 0 & -0.233595 & 10.21 & 10.22 \\
\hline 34 & 2-Methyl-1-butene & -0.175620 & -0.037029 & 0 & -0.239266 & 10.22 & 10.34 \\
\hline 35 & trans-4-Methyl-2-pentene & -0.105068 & -0.228773 & 0 & -0.235456 & 10.22 & 10.21 \\
\hline 36 & Sabinene & -0.143334 & -0.005605 & 0 & -0.221302 & 10.25 & 10.05 \\
\hline 37 & $\alpha$-Pinene & -0.120493 & -0.040878 & 0 & -0.218341 & 10.26 & 9.98 \\
\hline 38 & trans-4,4-Dimethyl-2-pentene & -0.126437 & -0.227621 & 0 & -0.232897 & 10.26 & 10.24 \\
\hline 39 & 1,4-Pentadiene & -0.091577 & -0.130875 & 0 & -0.240502 & 10.27 & 10.18 \\
\hline 40 & 2,3,3-Trimethylbutene & -0.174522 & -0.038531 & 0 & -0.239358 & 10.30 & 10.34 \\
\hline 41 & Longifolene & -0.146700 & -0.018208 & 0 & -0.229710 & 10.35 & 10.15 \\
\hline 42 & 1-Heptene & -0.140608 & -0.211285 & 0 & -0.246201 & 10.39 & 10.40 \\
\hline 43 & 1-Octene & -0.130345 & -0.197227 & 0 & -0.246141 & 10.40 & 10.37 \\
\hline 44 & 1-Hexene & -0.155653 & -0.233817 & 0 & -0.246307 & 10.43 & 10.46 \\
\hline 45 & 3-Methyl-1-butene & -0.157667 & -0.221693 & 0 & -0.249824 & 10.49 & 10.49 \\
\hline 46 & 1-Pentene & -0.154580 & -0.233360 & 0 & -0.246525 & 10.50 & 10.46 \\
\hline 47 & Ketene & -0.262671 & -0.177630 & 0 & -0.240468 & 10.76 & 10.65 \\
\hline 48 & 1-Bromoethene & -0.127509 & -0.135847 & 1 & -0.254441 & 11.17 & 11.17 \\
\hline \multirow[t]{2}{*}{49} & trans-1,2-Difluoroethene & -0.173960 & -0.332287 & 2 & -0.253777 & 12.13 & 12.13 \\
\hline & Test set & & & & & & \\
\hline 50 & a-Terpinene & -0.052336 & -0.054852 & 0 & -0.192386 & 9.44 & 9.53 \\
\hline 51 & Ocimene & -0.057367 & -0.083843 & 0 & -0.214890 & 9.60 & 9.79 \\
\hline 52 & $\alpha$-Humulene & -0.042641 & -0.001900 & 0 & -0.216163 & 9.65 & 9.73 \\
\hline
\end{tabular}




\begin{tabular}{|c|c|c|c|c|c|c|c|}
\hline 53 & Myrcene & -0.078040 & -0.005205 & 0 & -0.222559 & 9.67 & 9.89 \\
\hline 54 & 3-7-Dimethyl-1-6-octadiene & -0.051451 & -0.063437 & 0 & -0.223194 & 9.74 & 9.85 \\
\hline 55 & $\beta$-Phellandrene & -0.131298 & 0.003156 & 0 & -0.213643 & 9.78 & 9.93 \\
\hline 56 & 2-4-Dimethyl-1-3-butadiene & -0.133652 & 0.007906 & 0 & -0.214725 & 9.80 & 9.95 \\
\hline 57 & Limonene & -0.075281 & -0.003234 & 0 & -0.225634 & 9.84 & 9.91 \\
\hline 58 & 3-Methyl-1-3-pentadiene & -0.118096 & -0.101050 & 0 & -0.213908 & 9.87 & 9.95 \\
\hline 59 & 4-Methyl-1-3-pentadiene & -0.112913 & -0.100647 & 0 & -0.207910 & 9.88 & 9.88 \\
\hline 60 & trans-3-Methyl-2-pentene & -0.123210 & -0.064764 & 0 & -0.217403 & 9.91 & 9.99 \\
\hline 61 & 2-5-Norbornadiene & -0.065542 & -0.182030 & 0 & -0.216970 & 9.92 & 9.88 \\
\hline 62 & 1-2-Dimethylcyclohexene & -0.077024 & -0.077025 & 0 & -0.216046 & 9.93 & 9.85 \\
\hline 63 & trans-1-3-5-Hexatriene & -0.099162 & -0.081043 & 0 & -0.209238 & 9.95 & 9.84 \\
\hline 64 & cis-1-3-5-Hexatriene & -0.096628 & -0.072709 & 0 & -0.209994 & 9.96 & 9.84 \\
\hline 65 & cis-Ocimene & -0.084047 & -0.060893 & 0 & -0.214641 & 9.98 & 9.85 \\
\hline 66 & 2-Carene & -0.070809 & -0.050403 & 0 & -0.214811 & 10.00 & 9.81 \\
\hline 67 & cis-1-3-Pentadiene & -0.119947 & -0.113836 & 0 & -0.218090 & 10.00 & 10.01 \\
\hline 68 & 1-3-5-Cycloheptatriene & -0.066484 & -0.113412 & 0 & -0.212641 & 10.01 & 9.81 \\
\hline 69 & 2-Methyl-1-5-hexadiene & -0.079922 & -0.111475 & 0 & -0.241347 & 10.02 & 10.14 \\
\hline 70 & Cis-3-Methyl-2-pentene & -0.130291 & -0.052227 & 0 & -0.224349 & 10.03 & 10.07 \\
\hline 71 & 1-Methyl-1-cyclopentene & -0.127674 & -0.053838 & 0 & -0.223283 & 10.04 & 10.05 \\
\hline 72 & 2-Ethylbutene & -0.176768 & -0.040028 & 0 & -0.238794 & 10.05 & 10.34 \\
\hline 73 & D3-carene & -0.088817 & -0.041613 & 0 & -0.224523 & 10.06 & 9.96 \\
\hline 74 & trans-3-Hexene & -0.107116 & -0.235035 & 0 & -0.229750 & 10.08 & 10.15 \\
\hline 75 & cis-5-Decene & -0.114145 & -0.242064 & 0 & -0.231210 & 10.12 & 10.19 \\
\hline 76 & cis-3-Hexene & -0.112071 & -0.243793 & 0 & -0.231830 & 10.13 & 10.19 \\
\hline 77 & Methylketene & -0.189643 & -0.179891 & 0 & -0.222801 & 10.16 & 10.28 \\
\hline 78 & 1,3-Butadiene & -0.132465 & -0.134366 & 0 & -0.228950 & 10.17 & 10.16 \\
\hline 79 & Cyclopentene & -0.111133 & -0.249231 & 0 & -0.232844 & 10.17 & 10.20 \\
\hline 80 & trans-2-Heptene & -0.109973 & -0.237771 & 0 & -0.230412 & 10.17 & 10.17 \\
\hline 81 & 2-Methyl-1-pentene & -0.179815 & -0.038736 & 0 & -0.238959 & 10.20 & 10.35 \\
\hline 82 & 1,5-Hexadiene & -0.081874 & -0.123862 & 0 & -0.249422 & 10.21 & 10.24 \\
\hline 83 & trans-2-Butene & -0.106220 & -0.245143 & 0 & -0.235027 & 10.22 & 10.21 \\
\hline 84 & 3-Methyl-1,2-butadiene & -0.061527 & -0.142706 & 0 & -0.235227 & 10.24 & 10.05 \\
\hline 85 & 2-Methyl-1-propene & -0.178806 & -0.033716 & 0 & -0.239567 & 10.26 & 10.35 \\
\hline 86 & cis-2-Butene & -0.113766 & -0.256586 & 0 & -0.233323 & 10.26 & 10.22 \\
\hline 87 & Camphene & -0.163119 & -0.032538 & 0 & -0.233314 & 10.27 & 10.24 \\
\hline 88 & 2,3-Dimethyl-1-butene & -0.176179 & -0.038128 & 0 & -0.239239 & 10.28 & 10.34 \\
\hline 89 & $\operatorname{Bicycle}(2,2,1)$-2-heptene & -0.117920 & -0.251578 & 0 & -0.230925 & 10.31 & 10.20 \\
\hline 90 & cis-Cyclooctene & -0.106120 & -0.224366 & 0 & -0.231830 & 10.38 & 10.17 \\
\hline 91 & $\operatorname{Bicycle}(2,2,2)$-2-octene & -0.121856 & -0.255257 & 0 & -0.234580 & 10.39 & 10.25 \\
\hline 92 & 4-Methyl-1-pentene & -0.145724 & -0.201448 & 0 & -0.249101 & 10.42 & 10.44 \\
\hline 93 & 1-Decene & -0.106722 & -0.164607 & 0 & -0.246066 & 10.43 & 10.29 \\
\hline 94 & 1-Butene & -0.157549 & -0.236456 & 0 & -0.246661 & 10.50 & 10.47 \\
\hline 95 & 3,3-Dimethyl-1-butene & -0.156862 & -0.211956 & 0 & -0.249531 & 10.55 & 10.48 \\
\hline 96 & cis-1,3-Dichloroperopene & -0.056614 & -0.188993 & 1 & -0.266567 & 11.08 & 11.13 \\
\hline 97 & 1-Chloroethene & -0.142002 & -0.171226 & 1 & -0.262491 & 11.18 & 11.31 \\
\hline 98 & cis-1,2-Difluoroethene & -0.174089 & -0.334662 & 2 & -0.254139 & 12.15 & 12.14 \\
\hline
\end{tabular}


Table 2. Molecular descriptors and $-\log k_{\mathrm{OH}}$ values for 80 aromatics

\begin{tabular}{|c|c|c|c|c|c|c|}
\hline No. & Name & $E_{\text {номо }}$ & $Q_{\mathrm{H}}$ & Mor17v & Exp. & Pred. \\
\hline & Training set & & & & & \\
\hline 1 & Toluene & -0.235310 & 0.161810 & -0.152 & 11.22 & 11.33 \\
\hline 2 & N,N'-Dimethylaniline & -0.184365 & 0.162648 & -0.090 & 9.83 & 9.71 \\
\hline 3 & m-Cresol & -0.215015 & 0.405793 & -0.087 & 10.19 & 10.36 \\
\hline 4 & 2,5-Dimethylphenol & -0.210349 & 0.406046 & -0.152 & 10.10 & 10.08 \\
\hline 5 & 2,3-Dichlorophenol & -0.237327 & 0.415574 & 0.109 & 11.78 & 11.49 \\
\hline 6 & m-Xylene & -0.228412 & 0.161007 & -0.243 & 10.63 & 10.92 \\
\hline 7 & Bromobenzene & -0.241900 & 0.154319 & -0.089 & 12.11 & 11.69 \\
\hline 8 & 1,2,4-Trichlorobenzene & -0.254439 & 0.184731 & 0.102 & 12.26 & 12.44 \\
\hline 9 & p-Chloroaniline & -0.204776 & 0.322197 & 0.038 & 10.37 & 10.39 \\
\hline 10 & Benzonitrile & -0.266821 & 0.160515 & -0.103 & 12.48 & 12.51 \\
\hline 11 & 1,2,3-Trimethylbenzene & -0.226524 & 0.159394 & -0.277 & 10.49 & 10.80 \\
\hline 12 & Biphenyl & -0.222169 & 0.132068 & -0.172 & 11.14 & 10.90 \\
\hline 13 & 2,2'-Dichlorobiphenyl & -0.243109 & 0.156510 & -0.090 & 11.70 & 11.73 \\
\hline 14 & 2,4-Dichlorobiphenyl & -0.236357 & 0.178026 & -0.031 & 11.59 & 11.58 \\
\hline 15 & 2',3,4-Trichlorobiphenyl & -0.241204 & 0.164889 & 0.152 & 12.00 & 12.12 \\
\hline 16 & 2-Methylnaphthalene & -0.209415 & 0.161567 & -0.182 & 10.28 & 10.39 \\
\hline 17 & 1,4-Dichloronaphthalene & -0.224481 & 0.162327 & -0.049 & 11.24 & 11.16 \\
\hline 18 & 1,2,4-Trimethylbenzene & -0.221654 & 0.162312 & -0.317 & 10.49 & 10.55 \\
\hline 19 & t-Butylbenzene & -0.235255 & 0.147250 & -0.292 & 11.34 & 11.08 \\
\hline 20 & p-Cresol & -0.211012 & 0.405554 & -0.136 & 10.33 & 10.13 \\
\hline 21 & 2,4-Dichlorophenol & -0.233391 & 0.423640 & 0.063 & 11.97 & 11.25 \\
\hline 22 & 1,2-Dihydroxy-4-methylbenzene & -0.202513 & 0.426353 & -0.055 & 9.81 & 9.96 \\
\hline 23 & 4-Chlorobenzotrifluoride & -0.264730 & 0.165715 & -0.050 & 12.62 & 12.53 \\
\hline 24 & 1,2-Dihydroxybenzene & -0.203874 & 0.406360 & 0.002 & 9.98 & 10.15 \\
\hline 25 & 3,3'-Dichlorobiphenyl & -0.239759 & 0.157330 & 0.037 & 11.39 & 11.86 \\
\hline 26 & 2,2',3,5'-Tetrachlorobiphenyl & -0.249698 & 0.169308 & -0.001 & 12.10 & 12.11 \\
\hline 27 & 2,3-Dimethylnaphthalene & -0.206205 & 0.159029 & -0.271 & 10.11 & 10.11 \\
\hline 28 & p-Xylene & -0.225706 & 0.160255 & -0.208 & 10.84 & 10.90 \\
\hline 29 & m-Ethyltoluene & -0.229391 & 0.160315 & -0.369 & 10.72 & 10.71 \\
\hline 30 & 1-Phenyl-2-methyl-1-propene & -0.212499 & 0.167845 & -0.244 & 10.48 & 10.37 \\
\hline 31 & 2,4-Dimethylphenol & -0.206656 & 0.412267 & -0.209 & 10.15 & 9.83 \\
\hline 32 & p-Ethyltoluene & -0.226155 & 0.163692 & -0.374 & 10.92 & 10.59 \\
\hline 33 & p-Dichlorobenzene & -0.247840 & 0.165042 & 0.037 & 12.49 & 12.12 \\
\hline 34 & Dibenzo-p-dioxin & -0.196206 & 0.147746 & 0.176 & 10.83 & 10.66 \\
\hline 35 & 3,5-Dichlorobiphenyl & -0.240104 & 0.176852 & 0.001 & 11.38 & 11.77 \\
\hline 36 & p-Cymene & -0.226187 & 0.162981 & -0.293 & 10.82 & 10.75 \\
\hline 37 & 1,2-Dihydroxybenzene & -0.203874 & 0.406366 & 0.002 & 9.98 & 10.15 \\
\hline 38 & Benzyl alcohol & -0.241703 & 0.388807 & -0.152 & 10.64 & 11.18 \\
\hline 39 & 2-Naphthol & -0.205244 & 0.408348 & -0.042 & 9.77 & 10.11 \\
\hline \multirow[t]{2}{*}{40} & Acenaphthylene & -0.213398 & 0.134531 & -0.462 & 9.96 & 10.03 \\
\hline & Test set & & & & & \\
\hline 41 & trans-1-Phenyl-1-propene & -0.212697 & 0.157210 & -0.224 & 10.23 & 10.43 \\
\hline 42 & Phenol & -0.218943 & 0.406350 & -0.043 & 10.58 & 10.58 \\
\hline 43 & 2,3-Dimethylphenol & -0.211353 & 0.406310 & -0.131 & 10.10 & 10.15 \\
\hline
\end{tabular}




\begin{tabular}{|c|c|c|c|c|c|c|}
\hline 44 & 3,4-Dimethylphenol & -0.207982 & 0.159271 & -0.164 & 10.09 & 10.38 \\
\hline 45 & 1,2-Dihydroxy-3-methylbenzene & -0.200703 & 0.405596 & -0.045 & 9.69 & 9.96 \\
\hline 46 & Fluorobenzene & -0.243342 & 0.146155 & -0.042 & 12.16 & 11.85 \\
\hline 47 & m-Dichlorobenzene & -0.254309 & 0.178369 & 0.011 & 12.14 & 12.27 \\
\hline 48 & Aniline & -0.198155 & 0.317899 & -0.029 & 9.95 & 10.05 \\
\hline 49 & Diphenylamine & -0.186785 & 0.144370 & -0.038 & 9.71 & 9.93 \\
\hline 50 & Indane & -0.227288 & 0.150423 & -0.289 & 11.04 & 10.81 \\
\hline 51 & 2,3-Dihydrobenzofuran & -0.207605 & 0.164914 & -0.224 & 10.44 & 10.24 \\
\hline 52 & 3-Chlorobiphenyl & -0.231318 & 0.156809 & -0.072 & 11.28 & 11.36 \\
\hline 53 & 4,4'-Dichlorobiphenyl & -0.230332 & 0.157946 & -0.071 & 11.70 & 11.33 \\
\hline 54 & 2,4,5-Trichlorobiphenyl & -0.241571 & 0.184064 & 0.083 & 11.89 & 11.97 \\
\hline 55 & 2,2',4,4'-Tetrachlorobiphenyl & -0.250343 & 0.180982 & -0.024 & 12.00 & 12.06 \\
\hline 56 & 1,3,5-Trimethylbenzene & -0.225937 & 0.160058 & -0.314 & 10.24 & 10.70 \\
\hline 57 & o-Xylene & -0.229483 & 0.158403 & -0.215 & 10.86 & 11.02 \\
\hline 58 & Isopropylbenzene & -0.235675 & 0.149636 & -0.221 & 11.19 & 11.23 \\
\hline 59 & Methoxybenzene & -0.215159 & 0.168629 & -0.030 & 10.76 & 10.87 \\
\hline 60 & 2,6-Dimethylphenol & -0.210012 & 0.170326 & -0.155 & 10.18 & 10.45 \\
\hline 61 & n-Propylbenzene & -0.235056 & 0.144776 & -0.351 & 11.22 & 10.97 \\
\hline 62 & o-Dichlorobenzene & -0.251513 & 0.162814 & 0.066 & 12.38 & 12.31 \\
\hline 63 & 2,4-Toluenediamine & -0.180661 & 0.320196 & -0.034 & 9.72 & 9.43 \\
\hline 64 & 2-Chlorobiphenyl & -0.232209 & 0.155215 & -0.054 & 11.55 & 11.43 \\
\hline 65 & 2,4,4'-Trichlorobiphenyl & -0.239363 & 0.180098 & 0.051 & 11.96 & 11.84 \\
\hline 66 & o-Ethyltoluene & -0.229576 & 0.161476 & -0.362 & 10.91 & 10.73 \\
\hline 67 & Benzene & -0.246246 & 0.128582 & -0.086 & 11.91 & 11.89 \\
\hline 68 & Ethylbenzene & -0.234059 & 0.153817 & -0.230 & 11.15 & 11.15 \\
\hline 69 & 4-t-Butyltoluene & -0.226003 & 0.160343 & -0.339 & 10.86 & 10.66 \\
\hline 70 & o-Cresol & -0.213955 & 0.166169 & -0.101 & 10.38 & 10.70 \\
\hline 71 & 3,5-Dimethylphenol & -0.212285 & 0.405307 & -0.158 & 9.95 & 10.13 \\
\hline 72 & Chlorobenzene & -0.246366 & 0.155025 & -0.026 & 12.11 & 11.97 \\
\hline 73 & Tetralin & -0.228214 & 0.149512 & -0.359 & 10.46 & 10.71 \\
\hline 74 & 4-Chlorobiphenyl & -0.226420 & 0.155500 & -0.124 & 11.41 & 11.10 \\
\hline 75 & 2,4',5-Trichlorobiphenyl & -0.241429 & 0.166855 & 0.111 & 11.92 & 12.05 \\
\hline 76 & 1-Methylnaphthalene & -0.208493 & 0.162456 & -0.178 & 10.28 & 10.37 \\
\hline 77 & 2-Phenyl-1-propene & -0.221340 & 0.161206 & -0.222 & 10.28 & 10.72 \\
\hline 78 & 1-Naphthol & -0.199275 & 0.409567 & -0.050 & 9.26 & 9.89 \\
\hline 79 & 2,3-Benzofuran & -0.219410 & 0.159895 & -0.197 & 10.43 & 10.71 \\
\hline 80 & Styrene & -0.221666 & 0.144344 & -0.130 & 10.24 & 10.94 \\
\hline
\end{tabular}

\subsection{Molecular descriptors}

The molecular structure of each compound was sketched first using ChemBioDraw Ultra 11.0. Subsequently, the sketched structure was transferred to Chem3D module and pre-optimized using MM2 force field in ChemBio3D Ultra 11.0 until the minimum rms error became smaller than $0.100 \mathrm{kcal} / \mathrm{mol}$ $\AA$. The energy minimized molecules were then fully optimized and calculated using the B3LYP approach in combination with the 6-31G(d) basis set, ${ }^{19}$ within Gaussian 09 (Revision A.02). Lastly, two groups of descriptors were calculated for each molecule. One comprises 1664 molecular descriptors that are based on the fully optimized molecular structures and calculated by Dragon software. ${ }^{20}$ More information about the types of the molecular descriptors calculated with Dragon software can be found in Dragon software user's guide. ${ }^{20}$ The other is the quantum chemical descriptors including the molecular average polarizability $(\alpha)$, the molecular dipole moment $(\mu)$, the energy of the lowest unoccupied molecular orbital $\left(E_{\mathrm{Lumo}}\right)$, the energy of the highest occupied molecular orbital $\left(E_{\text {номо }}\right)$, the most positive net atomic charge on hydrogen atoms in a molecule $\left(Q_{\mathrm{H}}\right)$, the net charge of the most negative atom $\left(q^{-}\right)$and Fukui indices. The former six descriptors $\left(\alpha, \mu, E_{\text {Luмо }}, E_{\text {номо }}, Q_{\mathrm{H}}\right.$, and $q$ ) are presented in the modified theoretical linear solvation energy relationship model. ${ }^{21}$ For 98 alkenes $C_{1} R_{3} R_{4}=C_{2} R_{5} R_{6}\left(C_{1}\right.$ contains less pendent groups than $\mathrm{C}_{2}$ ), three types of Fukui indices were calculated for $\mathrm{C}_{1}$ and $\mathrm{C}_{2}$ atoms with following equations: ${ }^{22,23}$

$$
f_{r}^{-}=q_{r}^{N}-q_{r}^{N-1} \quad \text { (for electrophilic attack) }
$$




$$
\begin{gathered}
f_{r}^{+}=q_{r}^{N+1}-q_{r}^{N} \quad \text { (for nucleophilic attack) } \\
f_{r}^{0}=\left(q_{r}^{N+1}-q_{r}^{N-1}\right) / 2 \quad \text { (for radical attack) }
\end{gathered}
$$

where $r$ is the atom $\mathrm{C}_{1}$ or $\mathrm{C}_{2}, q_{r}^{N}, q_{r}^{N-1}$ and $q_{r}^{N+1}$ are, respectively, Mulliken atom charges of the neutral, cationic, and anionic species. Thus six Fukui indices were calculated for each alkene. Similarly, 21 Fukui indices for seven atoms were calculated for each aromatic compound. The seven atoms include the six $\mathrm{C}$ atoms in the benzene ring and the atom in substituents, which joins directly to the ring.

\subsection{Model development}

MLR was used to seek an optimum linear combination of variables from the descriptors calculated and develop a MLR model. ${ }^{24,25}$ Some important statistical parameters, such as the correlation coefficient $R$, standard error $S E$, $t$-test, variance inflation factor $(V I F)$ and Sig.-test (or $p$-value), were used to valuate the variables or models.

The leave-one-out (LOO) cross-validation procedure can be used to test the internally predictive ability of a QSAR model. In LOO each chemical is put in the test set once a time in every iterative validation: thus it is a test compound when it is predicted by the model developed on $n-1$ chemicals. A successful QSPR model should be validated with the test set and satisfies following criteria 26,27

$$
\begin{aligned}
& q_{\text {int }}{ }^{2}>0.5 \\
& q_{\text {ext }}{ }^{2}>0.5 \\
& R^{2}>0.6 \\
& \left(R^{2}-R_{0}^{2}\right) / \mathrm{R}^{2}<0.1 \text { or }\left(R^{2}-R_{0}^{\prime 2}\right) / \mathrm{R}^{2}<0.1 \\
& 0.85 \leq k \leq 1.15 \text { or } 0.85 \leq k^{\prime} \leq 1.15
\end{aligned}
$$

where $q^{2}$ is the predictive squared correlation coefficient $\left(q_{\mathrm{int}}{ }^{2}\right.$ for training sets, $q_{\text {ext }}{ }^{2}$ for external test sets), $R$ is the correlation coefficient, $R_{0}^{2}$ (predicted versus observed values) and $R_{0}^{\prime}{ }^{2}$ (observed versus predicted values) are coefficients of determination, $k$ and $k^{\prime}$ are slopes of regression lines through the origin of predicted versus observed and observed versus predicted respectively. Mathematical definitions of parameters $\left(q^{2}, R^{2}, R_{0}^{2}, R_{0}^{\prime}{ }_{0}^{2} k\right.$ and $\left.k^{\prime}\right)$ can be found in the literature. ${ }^{27,28}$

\section{RESULTS AND DISCUSSION}

\subsection{Statistical results}

An analysis of the rate constants $-\log k_{\mathrm{OH}}$ in the training sets of alkenes and aromatics with respect to respective descriptors resulted in the following best regression equations:

$$
\begin{aligned}
& -\log k_{\mathrm{OH}}=7.346-2.671 f_{1 \mathrm{C}}-0.486 f^{\prime}{ }^{2 \mathrm{C}}+0.749 N_{\mathrm{X}}-10.481 E_{\mathrm{HOMO}} \\
& R^{2}=0.938, s=0.108, F=166.530, N=49 \text { (For alkenes) } \\
& -\log k_{\mathrm{OH}}=3.865-34.141 E_{\mathrm{HOMO}}-1.660 Q_{\mathrm{H}}+1.943 \text { Mor } 17 v \\
& R^{2}=0.910, s=0.265, F=121.212, N=40 \text { (For aromatics) }
\end{aligned}
$$

The descriptors present in above models and corresponding values are shown in Tables 1 and 2; their meanings and statistical parameters are shown in Table 3. The results evaluated are listed in Table 4. Calculated values are listed in Tables 1 and 2, and plotted versus experimental values in Figs 1 and 2.

The Sig.-values in Table 3 suggests that all the descriptors in each model are significant; the $V I F$-test shows that the descriptors are not strongly correlated with each other. From Table 4, we can conclude that our results satisfy the above accept conditions (Eqs 4-8).

\subsection{Comparison of models}

In this paper, the rms errors of the training and test sets of alkenes are 0.102 and 0.114 , respectively. The mean $r m s$ error is 0.108 , which is closer to the results $(0.106 \sim 0.139)$ in other MLRs of alkenes. ${ }^{7,8}$ But our model includes more compounds and fewer descriptors. In addition, our model (Eq. 9) and Fatemi's models ${ }^{12}$ based on alkenes have the same data set. But the rms errors of the six QSAR models, based on five descriptors and evaluated by a leave-24-out cross-validation test, were above $0.16 .{ }^{12}$ Compared with other models in the literature, ${ }^{7,8,12}$ the present MLR model (Eq. 9) shows better statistical quality.

The rms errors of the training and test sets for aromatics in this paper are 0.282 and 0.260 , respectively. While the $r m s$ errors in previous models ${ }^{9-11,13}$

\begin{tabular}{|c|c|c|c|c|c|}
\hline Model & Symbol & Descriptor & $t$-test & Sig. & $V I F$ \\
\hline \multirow[t]{4}{*}{$\begin{array}{l}\text { Model for } \\
\text { alkenes }\end{array}$} & $f_{1 \mathrm{C}^{-}}^{-}$ & $\begin{array}{l}\text { The Fukui index of } \\
\mathrm{C}_{1} \text { atom based on } \\
\text { Mulliken charges }\end{array}$ & -5.871 & 0.000 & 1.459 \\
\hline & $f_{2 \mathrm{C}}^{\prime}$ & $\begin{array}{l}\text { The Fukui index of } \\
\mathrm{C}_{2} \text { atom based on } \\
\text { Mulliken charges } \\
\text { with hydrogens } \\
\text { summed into } \\
\text { heavy atoms }\end{array}$ & -2.454 & 0.018 & 1.331 \\
\hline & $N_{\mathrm{X}}$ & $\begin{array}{c}\text { The number of } \\
\mathrm{R}=\mathrm{CHX} \text { functional } \\
\text { group counts }\end{array}$ & 13.928 & 0.000 & 1.192 \\
\hline & $E_{\text {номо }}$ & $\begin{array}{l}\text { The energy of the } \\
\text { highest occupied } \\
\text { molecular orbital }\end{array}$ & -6.811 & 0.000 & 1.913 \\
\hline \multirow[t]{3}{*}{$\begin{array}{c}\text { Model } \\
\text { for } \\
\text { aromatics } \\
\end{array}$} & $E_{\text {номо }}$ & $\begin{array}{l}\text { The energy of the } \\
\text { highest occupied } \\
\text { molecular orbital }\end{array}$ & -13.693 & 0.000 & 1.238 \\
\hline & $Q_{\mathrm{H}}$ & $\begin{array}{l}\text { The most positive } \\
\text { net atomic charge } \\
\text { on hydrogen atoms } \\
\text { in a molecule }\end{array}$ & -3.879 & 0.000 & 1.313 \\
\hline & $\operatorname{Mor} 17 v$ & $\begin{array}{c}\text { 3D-MoRSE } \\
\text { descriptor (signal } \\
17 \text { / weighted by } \\
\text { atomic van der } \\
\text { Waals volumes) }\end{array}$ & 6.429 & 0.000 & 1.180 \\
\hline
\end{tabular}
containing aromatics and non-aromatics range between 0.391 and 0.501 , which are greater than the results in our model (Eq. 10). In addition, the squared correlation coefficient $\left(R^{2}=0.910\right)$ in Eq. 10 is greater than that $\left(r^{2}=0.735\right)$ of the 4-variable model of $k_{\mathrm{OH}}$ for aromatic pollutants in water matrix, ${ }^{29}$ which also suggests that our model (Eq. 10) is accurate.

Generally, a QSAR model of $k_{\mathrm{OH}}$, with rms values of around $0.35 \mathrm{log}$ units, can be considered acceptable for screening purposes. ${ }^{30}$ Obviously, the models obtained in this paper satisfy this criterion.

Table 3. List of descriptors in MLR models, meaning and statistical parameters.

\subsection{Applicability domain}

The Williams plots (i.e. plot of standardized residuals versus leverages) in Figs 3 and 4 were used to visualize respective applicability domains. Predictions for only those compounds that fall into this domain may be considered reliable. ${ }^{13,25}$ The leverage $h$ and warning leverage $h^{*}$ are defined with the following expressions ${ }^{13,31}$

$$
\begin{aligned}
& h_{\mathrm{i}}=x_{\mathrm{i}}^{T}\left(X^{T} X\right)^{-1} x^{\mathrm{i}}(i=1, \ldots, n) \\
& h^{*}=3(p+1) / n
\end{aligned}
$$

where $x_{\mathrm{i}}$ is the descriptor vector of the considered compound, $X$ is the model matrix derived from the training set descriptor values, $n$ is the number of training compounds and $p$ is the number of model parameters.

Generally, a value of 3 for standardized residual is used as a cut-off value for accepting predictions. High leverage points $\left(h_{\mathrm{i}}>h^{*}\right)$ with small standardized residuals $(<3 \sigma)$ are taken as good high leverage points or good influence points, which stabilize the model and make it more precise. While high leverage points with large standardized residuals $(>3 \sigma)$ are called bad high leverage points or bad influence points. ${ }^{31}$ For alkenes, Fig. 3 shows that two chemicals in the training set have leverage values greater than the warning leverage $h^{*}(=0.306)$. But their $\sigma$ values are less than 3 . Thus these points can stabilize the model and make it more accurate. In addition, the two chemicals with $h>h^{*}$ and $\sigma<3$ in the test set suggest that the MLR model of alkenes has good generalizability. ${ }^{13,31}$ Similarly, as can be seen from Fig. 4 , there is only one chemical with $h>h^{*}(=0.300)$ and $\sigma<3$ in the training set, which exerts a large influence on the model of aromatics. 
Table 4. Results evaluated for the two models

\begin{tabular}{|c|c|c|c|c|c|c|c|c|}
\hline Model & $q_{\text {int }}{ }^{2}$ & $q_{\mathrm{ext}}{ }^{2}$ & $R^{2}$ & $R_{0}{ }^{2}$ & $R_{0}{ }^{2}$ & $k$ & $k$ & $r m s$ \\
\hline Model for alkenes & 0.925 & 0.928 & 0.930 & 0.927 & 0.929 & 1.001 & 0.999 & 0.108 \\
\hline Model for aromatics & 0.886 & 0.903 & 0.916 & 0.879 & 0.908 & 1.005 & 0.994 & 0.260 \\
\hline
\end{tabular}

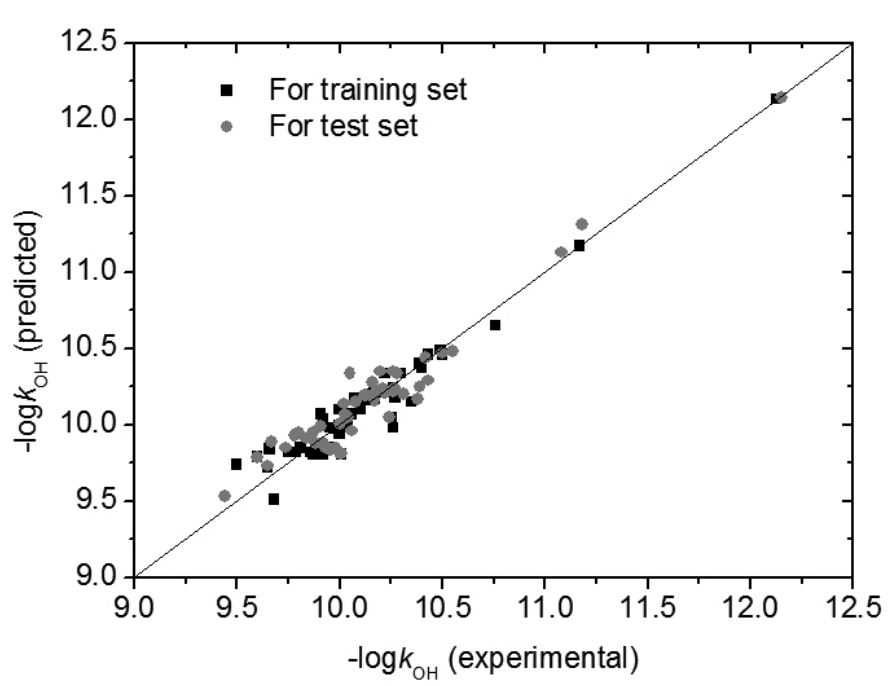

Figure 1. Plot of calculated vs. experimental $-\log k_{\mathrm{OH}}$ values of alkenes.

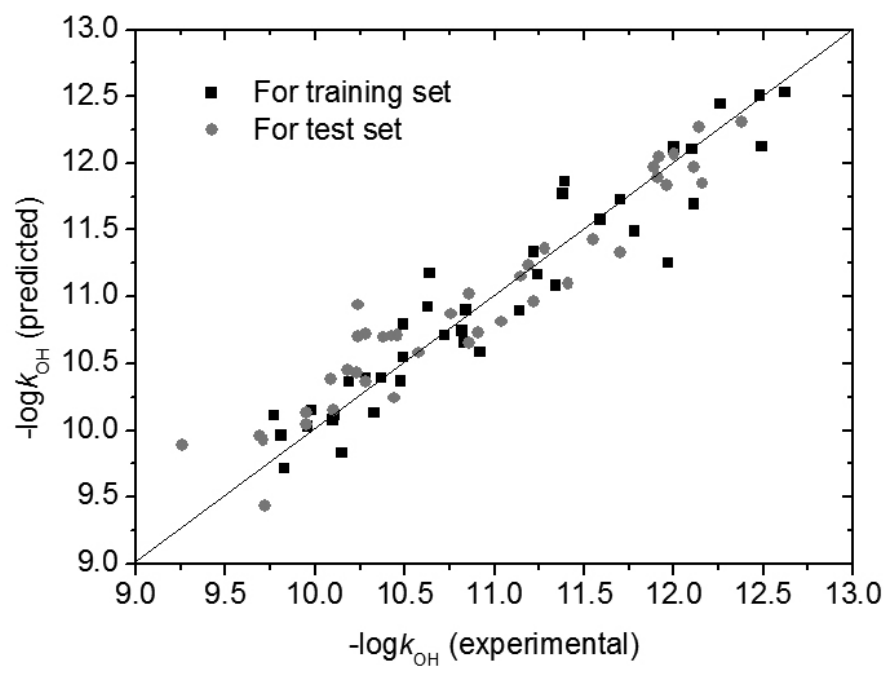

Figure 2. Plot of calculated vs. experimental $-\log k_{\mathrm{OH}}$ values of aromatics.

\subsection{Mechanistic interpretation}

For the degradation reactions of alkenes, $\mathrm{OH}$ radical addition to double bond is the dominant reaction pathway: $\mathrm{OH}+\mathrm{C}_{1} \mathrm{R}_{3} \mathrm{R}_{4}=\mathrm{C}_{2} \mathrm{R}_{5} \mathrm{R}_{6} \rightarrow \mathrm{C}_{1}(\mathrm{OH}) \mathrm{R}_{3} \mathrm{R}_{4}-$ ${ }^{\circ} \mathrm{C}_{2} \mathrm{R}_{5} \mathrm{R}_{6}$. According to the classic structure-activity relationship, the chemical reactivity of vinyl compounds is determined by electronic and steric effects of substituents. Electronic effects include inductive and conjugated effects. ${ }^{29}$ Steric effects include the size, position and number of substituents. Electrondonor substituents of alkenes can increase the electron density of double bonds, activate $\pi$ bonds, and result in high degradation rates for electrophilic attack by $\mathrm{OH}$ radical. In addition, conjugated double bonds of alkenes increase electron mobility, inductive effect, molecular polarizability and degradation rates. Therefore, from Table 1, we can find the trend that dialkenes have higher rate constants that monoolefines. The synergistic effects of electrondonor substituents and conjugated double bonds increase reaction rates. For example, $\alpha$-Phellandrene $\left(-\log k_{\mathrm{OH}}=9.50\right)($ No. 1 in Table 1$)$ and $\alpha$-Terpinene

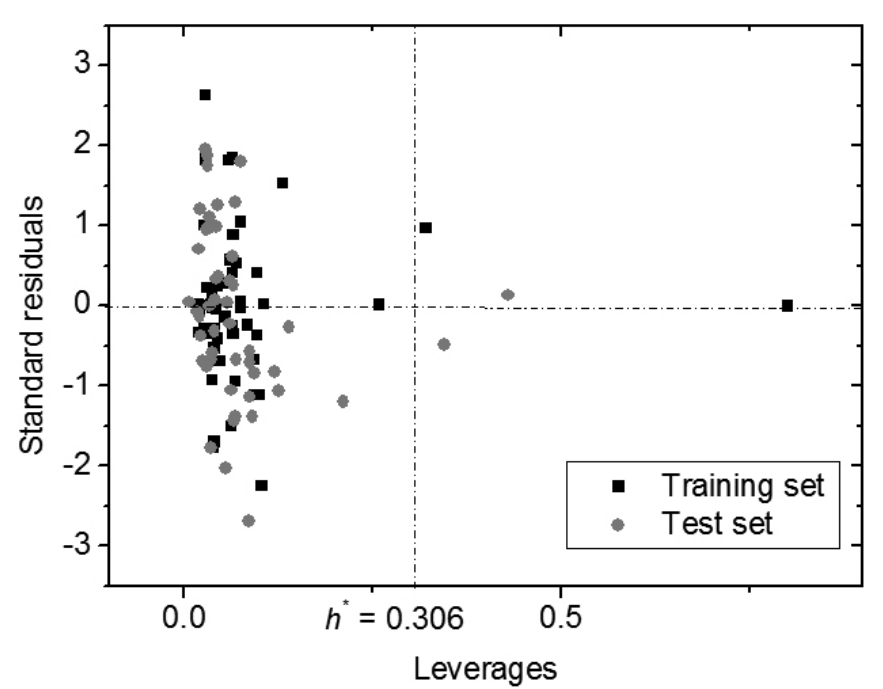

Figure 3. Williams plot for the model of alkenes.

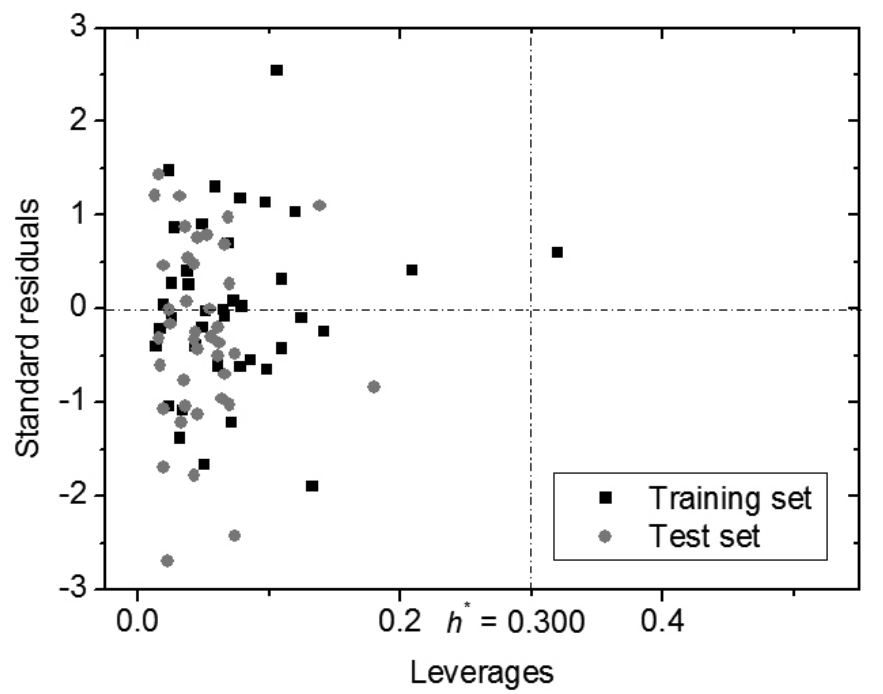

Figure 4. Williams plot for the model of aromatics.

$\left(-\log k_{\mathrm{OH}}=9.44\right)$ (No. 50) are the most reactive systems and have the highest rate constants. On the contrary, electron--acceptor groups of alkenes such as halogen and carbonyl substituents deactivate double bonds and consequently decrease the degradation of chemicals. For example, 1-Bromoethene (No. 48 in Table 1), trans-1,2-Difluoroethene (No. 49), 1-Chloroethene (No. 97), and cis-1,2-Difluoroethene (No. 98) are the least reactive molecules and have the lowest rate constant values.

By the $t$-test (see Table 3), the most significant descriptor in Eq. 9 is $N_{\mathrm{X}}$, which denotes the number of $\mathrm{R}=\mathrm{CHX}$ functional group and reflects the number of halogen atoms. ${ }^{20}$ Halohydrocarbons are classic electrophilic reagents, which are not susceptible to electrophilic attack. Therefore, the molecules with more $\mathrm{R}=\mathrm{CHX}$ groups tend to have lower $k_{\mathrm{OH}}$ values. The second significant descriptor appearing in Eq. 9 is $E_{\text {номо }}$. The descriptor $E_{\text {номо }}$ governs many chemical reactions and characterizes the susceptibility of the molecule toward attack by electrophiles. ${ }^{6}$ The $\mathrm{OH}$ radical is an electrophilic reagent during the 
reactions of alkenes with $\cdot \mathrm{OH}$ by the radical addition to the $>\mathrm{C}=\mathrm{C}<$ double bond. An alkene compound with a larger $E_{\text {номо }}$ tends to lose electrons and leads to increased susceptibility of ${ }^{\circ} \mathrm{OH}$ attacking and consequently a high $k_{\mathrm{OH}}$ value. ${ }^{13,15}$ Thus, the descriptor $E_{\text {номо }}$ is positively correlated with $k_{\mathrm{OH}}$.

According to the $t$-test, the next two significant descriptors $f_{1 \mathrm{C}}{ }^{-\mathrm{OH}^{\prime}}{ }^{-} f^{\prime}{ }_{2 \mathrm{C}}{ }^{-}$are Fukui indices of $\mathrm{C}_{1}$ and $\mathrm{C}_{2}$ atoms for electrophilic attack, respectively. Fukui indices are very useful in characterizing the location of the reactive regions as well as either the nucleophilic or electrophilic behavior. A larger value of Fukui index $f_{1 \mathrm{C}}{ }^{-}$(or $f_{2 \mathrm{C}}{ }^{-}$) indicates a higher reactivity for $\mathrm{C}_{1}\left({ }^{\circ} \mathrm{C}_{2}\right)$ atom. Fukui indices $f_{1 C^{-}}$and $f_{2 C}^{\prime}$ are correlated with $k_{\mathrm{OH}}$, which suggests that both $\mathrm{C}_{1}$ and $\mathrm{C}_{2}$ exhibit high reactivity when $\mathrm{OH}$ radical attacks double bonds of alkenes.

As a strong electrophilic species, $\mathrm{OH}$ radical reacts with aromatic compounds by following two routs (Scheme 1). ${ }^{1}$ One is $\mathrm{H}$-atom abstraction from the $\mathrm{C}-\mathrm{H}$ bond of alkyl substituent group (Scheme 1 (a)). The other is the $\mathrm{OH}$ radical addition to one of double bonds from the benzene rings (Scheme 1 (b)). Above all, we take aromatic compounds with only one substituent as examples to analyze substituent effects. Aromatics with electron-donor groups $-\mathrm{N}\left(\mathrm{CH}_{3}\right)_{2}(9.83),-\mathrm{NH}_{2}(9.95),-\mathrm{OH}(10.58),-\mathrm{OCH}_{3}(10.76),-\mathrm{CH}_{2} \mathrm{CH}_{3}(11.15)$, $-\mathrm{CH}\left(\mathrm{CH}_{3}\right)_{2}$ (11.19), $-\mathrm{CH}_{3}(11.22),-\mathrm{CH}_{2} \mathrm{CH}_{2} \mathrm{CH}_{3}(11.22),-\mathrm{C}\left(\mathrm{CH}_{3}\right)_{3}(11.34)$ possess higher degradation rate $k_{\mathrm{OH}}$ values (or lower $-\log k_{\mathrm{OH}}$ values) than Benzene (11.91). The above values in the parentheses are the corresponding $-\log k_{\mathrm{OH}}$ values. While the compound Benzonitrile with a electron-acceptor substituent $-\mathrm{CN}$ has a low $k_{\mathrm{OH}}$ value (12.48). The same trends can be found in other aromatic compounds. These phenomena can be explained by electronic effects of substituents, i.e., electron-donor substituents can activate the benzene ring and increase susceptibility of ${ }^{\circ} \mathrm{OH}$ attacking, and on the contrary, electronacceptor substituents shift the electron density and deactivate the benzene ring. ${ }^{29}$ In addition, Naphthalenes have greater molecular polarizability and higher reaction activity than Benzene. Therefore, it is easy to understand that the compound 1-Naphthol with the strong electron-donor group -OH shows the highest $k_{\mathrm{OH}}$ value $\left(-\log k_{\mathrm{OH}}=9.26\right)$ among 80 aromatics (see Table 2). All the halogen derivatives have low $k_{\mathrm{OH}}$ values, especially for these compounds with multiple halogen substitutions. For example, 4-Chlorobenzotrifluoride ($\left.\log k_{\mathrm{OH}}=12.62\right)$ and p-Dichlorobenzene $\left(-\log k_{\mathrm{OH}}=12.49\right)$ show the lowest $k_{\mathrm{OH}}$ values. The reasons are that halogen substituents are electron-acceptor groups and multiple halogen groups have synergistic effects on deactivating benzene rings, and furthermore, decreasing $k_{\mathrm{OH}}$ values.

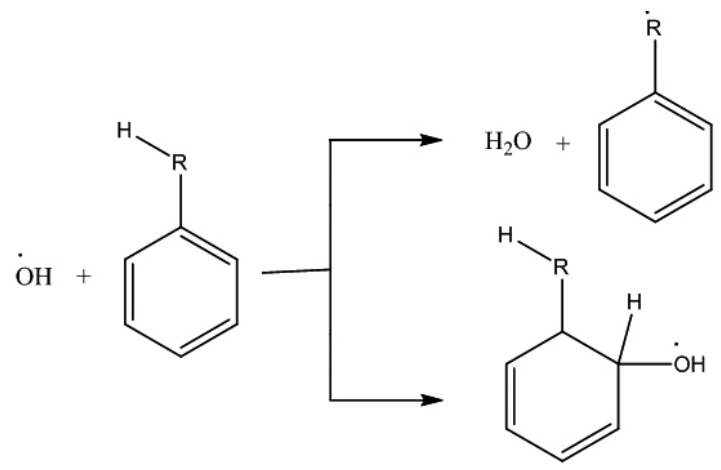

Scheme 1. The reaction routs for aromatic compounds with $\mathrm{OH}$ radical.

For the model (Eq. 10) of aromatics, the most significant descriptor is $E_{\text {Homo }}$. As stated above, $E_{\text {Hovo }}$ is positively related to $k_{\mathrm{OH}}$. The next one is the 3D MoRSE (3D Molecule Representation of Structures based on Electron diffraction) descriptor Mor 17v (signal 17/weighted by atomic van der Waals volumes). Mor $17 v$ retains important structural features such as the mass and the amount of branching. ${ }^{20} \mathrm{An}$ increase in Mor $17 v$ causes an increase in the steric hindrance between the molecule and $\mathrm{OH}$ radical. Therefore, the degradation rate constant decreases. The last significant descriptor in Eq. 10 is $Q_{\mathrm{H}}$. It denotes the most positive net atomic charge on hydrogen atoms. Generally, local electron densities or charges are used as static chemical reactivity indices and describe molecular polarizability. ${ }^{6}$ The greater the net charge on $\mathrm{H}$ atom is, the higher the reactivity. Thus $k_{\mathrm{OH}}$ increases with increasing $Q_{\mathrm{H}}$.

\section{CONCLUSIONS}

General QSAR models based on the MLR approach were developed for reaction rate constants of ${ }^{\circ} \mathrm{OH}$ with 98 alkenes and 80 aromatics in the atmosphere. The two QSAR models were proved to be accurate and reliable.
For the model for $k_{\mathrm{OH}}$ of alkenes, the most significant descriptor is the number of R=CHX functional group counts, $N_{\mathrm{x}}$. The group deactivates the double bond and decreases the reaction rate. The second descriptor $E_{\text {номо }}$ characterizes the susceptibility of the molecule toward attack by electrophiles. A larger $E_{\text {номо }}$ tends to lose electrons and facilitates the degradation of chemicals. Fukui indices of $\mathrm{C}_{1}$ and $\mathrm{C}_{2}$ atoms $\left(f_{1 C^{-}}\right.$and $\left.f^{\prime}{ }^{-}\right)$characterize the location of the reactive regions for electrophilic attack. A larger value of Fukui index $f_{1 \mathrm{C}}{ }^{-}$(or $f_{2 C}^{\prime}$ ) indicates a higher reactivity for $\mathrm{C}_{1}\left(\right.$ or $\left.\mathrm{C}_{2}\right)$ atom.

For the model for $k_{\mathrm{OH}}$ of aromatics, the main contribution to degradation rates is $E_{\text {номо. }}$. A larger $E_{\text {номо }}$ results in a higher $k_{\mathrm{OH}}$. The topological descriptor Mor $17 v$ encodes molecular structure and steric hindrance. A larger descriptor Mor $17 v$ indicates greater steric hindrance and consequently decreases the reaction rate constant. $Q_{\mathrm{H}}$ can reflect molecular reactivity and polarizability. Thus, the descriptors in each MLR model have clear physical meanings and represent respective major factors affecting the degradation rates $k_{\mathrm{OH}}$.

\section{ACKNOWLEDGEMENTS}

We thank the financial supports from the Science Foundation of Hunan Province (Grant No. 2010FJ4116), Hunan Provincial Natural Science Foundation of China (Grant No. 12JJ6011), and the National Natural Science Foundation of China (Grant No. 20972045).

\section{REFERENCES}

1. R. Atkinson, Atmos. Environ. 41, S200, (2007).

2. P. Gramatica, V. Consonni, R. Todeschini, Chemophere 38, 1371, (1999).

3. P. Gramatica, P. Pilutti, E. Papa, SAR QSAR Environ. Res. 13, 743, (2002).

4. W. M. Meylan, P. H. Howard, Environ. Toxicol. Chem. 22, 1724, (2003).

5. A. Böhnhardt, R. Kühne, R.-U. Ebert, G. Schüürmann, Theor. Chem. Acc. 127, 355, (2010).

6. M. Karelson, V. S. Lobanov, A. R. Katritzky, Chem. Rev. 96, 1027, (1996).

7. G. A. Bakken, P. C. Jurs, J. Chem. Inf. Comput. Sci. 39, 1064, (1999).

8. M. Pompe, M. Veber, M. Randić, A. T. Balaban, Molecules 9, 1160, (2004).

9. P. Gramatica, P. Pilutti, E. Papa, Atmos. Environ. 38, 6167, (2004).

10. P. Gramatica, P. Pilutti, E. Papa, J. Chem. Inf. Comput. Sci. 44, 1794, (2004).

11. T. Öberg, Atmos. Environ. 39, 2189, (2005).

12. M. H. Fatemi, E. Baher, SAR QSAR Environ. Res. 20, 77, (2009).

13. Y. N. Wang, J. W. Chen, X. H. Li, B. Wang, X. Y. Cai, L. P. Huang, Atmos. Environ. 43, 1131, (2009).

14. C. L. Yan, J. W. Chen, L. P. Huang, G. H. Ding, X. Y. Huang, Chemosphere 61, 1523, (2005)

15. X. X. Long, J. F. Niu, Chemosphere 67, 2028, (2007).

16. P. Gramatica, P. Pilutti, E. Papa, Atmos. Environ. 37, 3115, (2003).

17. M. Pompe, M. Veber, Atmos. Environ. 35, 3781, (2001).

18. M. H.Fatemi, Anal. Chim. Acta 556, 355, (2006).

19. X. L.Yu, B. Yi, X. Y. Wang, Z. M. Xie, Chem. Phys. 332, 115, (2007).

20. R. Todeschini, V. Consonni, A. Mauri, M. Pavan, DRAGON Professional, Version 5.4. Talete srl: Milan, 2006.

21. J. W. Chen, L. Feng, Y. Y. Liao, S. K.Han, L. S. Wang, Chemosphere 33, 537, (1996)

22. R. G. Parr, W. Yang, J. Am. Chem. Soc. 106, 4049, (1984).

23. B. Gómez, N. V. Likhanova, M. A. Domínguez Aguilar, O. Olivares, J. M. Hallen, J. M. Martínez-Magádn, J. Phys. Chem. A 109, 8950, (2005)

24. X. L. Yu, B. Yi, X. Y. Wang, J. Comput. Chem. 28, 2336, (2007).

25. X. L. Yu, B. Yi, X. Y. Wang, J. F. Chen, Atmos. Environ. 51, 124, (2012).

26. A.Golbraikh, A. Tropsha, J. Mol. Graph. Model. 20, 269, (2002).

27. A. Tropsha, P. Gramatica, V. K. Gombar, OSAR Combi. Sci. 22, 69, (2003).

28. X. L. Yu, B. Yi, W. H. Yu, X. Y. Wang, Chem. Pap. 62, 623, (2008).

29. H. Kušić, B. Rasulev, D. Leszczynska, J. Leszczynski, N. Koprivanac, Chemosphere 75, 1128, (2009).

30. A. Böhnhardt, R. Kühne, R.-U. Ebert, G. Schüürmann, J. Phys. Chem. A 112, 11391, (2008)

31. L. Eriksson, J. Jaworska, A. P. Worth, M. T. D. Cronin, R .M. McDowell, P. Gramatica, Environ. Health Perspect. 111, 1361, (2003). 